University of Nebraska - Lincoln

DigitalCommons@University of Nebraska - Lincoln

1984

\title{
Mutations, the Abberant Ratio Phenomenon, and Virus Infection of Maize
}

Myron K. Brakke

University of Nebraska-Lincoln

Follow this and additional works at: https://digitalcommons.unl.edu/plantpathpapers

Part of the Plant Pathology Commons

Brakke, Myron K., "Mutations, the Abberant Ratio Phenomenon, and Virus Infection of Maize" (1984).

Papers in Plant Pathology. 163.

https://digitalcommons.unl.edu/plantpathpapers/163

This Article is brought to you for free and open access by the Plant Pathology Department at DigitalCommons@University of Nebraska - Lincoln. It has been accepted for inclusion in Papers in Plant Pathology by an authorized administrator of DigitalCommons@University of Nebraska - Lincoln. 


\section{MUTATIONS, THE ABBERANT RATIO PHENOMENON, AND VIRUS INFECTION OF MAIZE ${ }^{1}$}

\section{Myron K. Brakke}

Agricultural Research Service, United States Department of Agriculture, and Plant Pathology Department, Nebraska Agricultural Experiment Station, University of Nebraska, Lincoln, Nebraska 68583

Viruses interact genetically in various ways with bacterial and animal hosts, e.g. by lysogeny in bacteriophage and by incorporating a DNA copy of retrovirus RNA into the host genome. These phenomena lead to mutations, to the ransfer of host genes by viruses, and to latent viruses being transmitted from generation to generation essentially as host genes. In contrast, there are no known examples of the incorporation of viral genomes into plant DNA.

The most likely candidate for genetic interaction between plants and viruses is the increased number of mutations in maize associated with barley stripe mosaic virus (BSMV) infection reported by Sprague et al (51). Research on this infection was begun in 1960 , but its history goes back to the time when $\mathrm{H}$. $\mathrm{H}$. McKinney was a graduate student investigating yellow spots in tobacco leaves infected with mosaic virus. McKinney was convinced that the yellow spots resulted from mutations in the virus $(31,32)$. This implied that viruses had a genetic system similar to that of plants and animals, a radical idea at a time when viruses were considered a mysterious non-particulate infectious fluid. McKinney retained a life-long interest in the genetics of viruses, in the similarity of virus symptoms in plants to mutations, and in the possibilities for genetic interaction between plants and viruses $(8 ; \mathrm{H}$. H. McKinney, personal memoirs, privately published).

\footnotetext{
'Published with the approval of the director as paper no. 7284, Journal Series, Nebraska Agricultural Experiment Station. Joint contribution of the Agricultural Research Service, US Department of Agriculture, and the Nebraska Agricultural Experiment Station.
} 
The opportunity to test for genetic interaction did not occur until McKinney secured the collaboration of Sprague, a maize geneticist. Maize was the obvious plant to use because its genetics were well known. BSMV was one of the few viruses known to infect corn at the time; it was probably selected because it is seed-and pollen-bome in barley and therefore might infect germ line cells. McKinney \& Sprague found a correlation between virus infection and mutations and concluded that the virus was mutagenic (51). A short description of the viruses and pertinent aspects of maize genetics will be given before their results are discussed.

\section{Pertinent Maize Genetics}

For more complete information on maize genetics, the reader may consult Coe $\&$ Neuffer $(13,37)$. Maize is a diploid with ten pairs of chromosomes; it produces haploid spores that develop into short-lived gametophytes, a threenucleate pollen grain with two sperm nuclei and an eight-nucleate embryo sac with an egg. The three nuclei of a pollen grain are genetically identical, as are the eight nuclei of an embryo sac. One sperm nucleus fuses with the egg nucleus in the embryo sac to give the embryo. The endosperm is triploid, arising from the fusion of the other sperm nucleus with a nucleus of the embryo sac that has been formed by the earlier fusion of two nuclei. In a few percent of the kernels, depending on the maize line, the phenotype of the endosperm differs from the genotype of the embryo, indicating fertilization of embryo and endosperm by nuclei from different pollen grains (heterofertilization) (48).

Many genetic studies on maize, including those on virus-induced mutations, rely heavily on kemel characters, and particularly on endosperm characters, which are more easily and quickly read than characters of plants grown from the kemels. Anthocyanin color in the aleurone layer of the endosperm requires dominant alleles at eight loci, $a 1, a 2, c 1, c 2, r, b z 1, b z 2, v p$, and $r$. There is evidence that $C 2$ is the structural gene for chalcone synthase, whereas $v p, c l$, and $r$ are regulatory genes $(11,15,16)$. Anthocyanin color is purple in the presence of $P r$, red with homozygous $p r$. Three loci affecting starch formation have been used in the virus studies. Sh conditions a plump kemel and is the structural gene for sucrose synthetase (12). The recessive allele, sh (shrunken), conditions a smooth, indented kemel. At another locus, $S u$ conditions a plump kemel, and su (sugary) a wrinkled, sweet one. Only amylopectin, staining red with iodine, is formed in the presence of $w x$ (waxy), while some amylose, staining purple with iodine, is formed with $W x$, the structural gene for starchbound nucleoside diphosphate glucose-starch glucosetransferase (53). Adh-1 is a structural gene for alcohol dehydrogenase. Since $A d h-1$ is expressed in pollen and the enzyme produces acrylaldehyde, which is lethal, from allyl alcohol, a mass selection scheme for pollen with a recessive allele, $a d h-1$, is possible (23, 45). 
Of all the above loci, $a l$ has been the one most frequently used in aberrant ratio (AR) research. Studies of this locus (designated as $a$ ) will be used as a specific example of AR to simplify the discussion.

Maize has a number of genetic loci that control deviations from standard Mendelian behavior. It has loci that control mutability and several systems of "controlling elements" [reviewed in $(18,20)]$. These latter are transposable sections of DNA whose insertion or excision from the chromosome controls expression of adjacent genes. Two elements are often involved; one, termed receptor, is cis, i.e. adjacent to the controlled gene, and the other, the regulator, is trans, i.e. anywhere in the genome. While the biochemical mechanism of action of maize-controlling elements has not been proven, they are probably similar to those of Drosophila and bacteria $(42,47)$. If this hypothesis is correct, the regulator codes for an enzyme, a transposase, which removes or inserts sections of DNA with appropriate, recognizable (by the enzyme) terminal sequences. These sequences would be present on the regulator, which is removed or inserted in one-element systems, and also on the receptor. One of the best known controlling element systems is Ac(trans)-ds(cis). One of the many ds elements (a receptor) has a base sequence similar to that of Ac but is shorter because of an internal deletion (19). Frequently, for unknown reasons, the regulator is expressed at a certain stage in kernel development to give roughly synchronous somatic mutations in a limited number of endosperm cells. The result is, for example, a spotted aleurone, each colored spot being of similar size and each composed of the descendants of one cell in which the mutation occurred. The phenotype of the spot depends on the gene in which the element was inserted and now becomes excised, and the size depends on the timing of the mutation. An early expression could give a kernel of uniform phenotype differing from the genotype of the embryo, as in heterofertilization (P. A. Peterson, personal communication). Controlling elements can also be expressed at other stages of development, but the effects are not as obvious as those of multiple somatic endosperm mutations.

\section{The Viruses}

Barley stripe mosaic virus (BSMV) has a genome of three positive-strand ssRNA molecules $(25,26)$. Various strains of the virus have two, three, or four electrophoretically distinct RNA components $(27,28)$. Each RNA component is separately encapsidated in a stiff, hollow, rod-shaped virion whose length depends on the size of the RNA (3). In strains with two electrophoretic components, genomic RNAs II and III have nearly the same size. The fourth electrophoretic component found in the Argentine Mild strain (BSMV-Am) has base sequences homologous to those of RNA III and may be a defective RNA III (29a). The ND18 strain, which can also induce mutations (40), has three electrophoretic components, a fact which shows that mutagenesis does not 
require RNA IV. BSMV is seed- and pollen-borne in barley and wheat, but not in corn $(40,49,51)$. It has no known arthropod, fungal, or nematode vectors. Seed from BSMV-infected barley and wheat has been reported to have an increased incidence of triploids and aneuploids $(29,44)$.

There are no reports of natural BSMV infection of maize. Some lines of corn can be infected by manual inoculation and develop a coarse mosaic with broad yellow and green areas $(33,40,51)$. The infection is temperature sensitive and plants kept at $35^{\circ} \mathrm{C}$ do not develop symptoms (4). The virus invades maize plants poorly and upper leaves frequently are free of symptoms and recoverable virus $(33,40)$. The virus seems to be confined to yellow areas of leaves and even there is present in low concentration when the leaves are young; it can be recovered only with difficulty from old leaves.

Wheat streak mosaic virus (WSMV) has a positive-strand, single-component ssRNA genome of $\mathrm{Mw} 2.8 \times 10^{6}$ and flexuous, rod-shaped virions $700 \mathrm{~nm}$ long $(1,2)$. It is neither seed- nor pollen-transmitted but is transmitted by an eriophyid mite, Aceria tulipae Kiefer, and is a common and destructive virus disease of wheat (1). About $40 \%$ of corn inbreds and a somewhat smaller percentage of hybrids are susceptible to WSMV (M. Brakke, unpublished observation). Field infection of corn is sporadic, usually produces a mild disease, but may be common and severe in susceptible inbreds in seedproduction fields in some years. Many lines of corn resistant at $25^{\circ} \mathrm{C}$ are susceptible at $35^{\circ} \mathrm{C}(4)$.

Maize dwarf mosaic virus (MDMV) is similar in the structural properties of its virion and RNA to WSMV but is transmitted by aphids (39). The virion coat protein differs in molecular weight from that of WSMV and the two viruses are not serologically related. MDMV is now common in corn fields in the corn belt of the United States. It can be isolated from up to $100 \%$ of randomly sampled mature com plants in Nebraska, many of which are symptomless and presumably were infected too late to develop symptoms (M. Brakke, R. G. Samson, unpublished observation).

Nothing is known of the properties of corn lily fleck virus, which has been lost.

\section{Mutations Associated with Virus Infection}

In their research showing a correlation between virus infection and a high mutation rate, Sprague \& McKinney used a homozygous dominant stock, $A$ A2 $C l C 2 R \operatorname{Pr} S u$ Sh Wx B Pl, that was susceptible to BSMV-Am, the most infectious strain on corn $(49,50,51)$ (G. F. Sprague, personal communication). This line was an outcross derivative of a high haploid line from E. H. Coe, Jr. The line was originally variable in susceptibility to BSMV, but a subline was selected by propagation from virus-infected individuals that were more uniformly susceptible (H. H. McKinney. G. F. Sprague, personal com- 
munication). The plants infected with BSMV-Am were too sick to set useable ears and so were used as male parents for crosses to lines with recessive alleles at various of the above loci (Figure 1). The standard female parent was al $A 2$ C1 C2 R pr su wx and was resistant or immune to BSMV and partly resistant to WSMV (G. F. Sprague, personal communication; 4). This stock had been used by Stadler \& Sprague (52) to study mutation induced by ultraviolet radiation. The female parent in the first report was given as a/a su/su pr/pr (50). The F1 progeny kernels should have been plump and fully colored purple. A number of kernels did not express the dominant phenotypes, either in part of the kernel (fractional) or the entire kernel (entire) (Table 1). By scoring the fractionals as $1 / 4$ or $1 / 2$ and so forth, the results in Table 1 could be combined to a single frequency, 1:108 in progeny from virus-treated plants and 1:556 in the control, a difference significant at the $1 \%$ level. The mutation rate from the virusinfected plants was about half that previously observed by Stadler \& Sprague (52) for ultraviolet radiation.

To confirm these mutations and detect additional mutations, $\mathrm{Fl}$ seeds were planted and the plants selfed to produce F2 progeny. These kernels should have segregated 3:1 for the marker phenotypes. Sprague et al (51) examined the F2 ears for kernel phenotype, planted a sample of seeds (25-50), and observed the seedlings for mutants. Among 1000 F2 control ears examined, none showed distortions in segregation ratios of the three loci and only three mutants were observed, two white and one virescent seedling. In contrast, in the $1000 \mathrm{~F} 2$ ears from the virus-treated series, abnormal segregation ratios (tentative $A R$ ) of the marker loci were observed, as well as an unspecified number of seedling and endosperm mutants. These included vivipary, aleurone color, and white and virescent seedlings. F2 frequencies suggested that these mutations were monogenic, and limited F3 progeny tests supported this supposition (51).

In subsequent research, Sprague \& McKinney $(49,50)$ concentrated efforts

Table 1 Frequencies of entire and fractional deficiencies in progenies involving healthy and virus-infected male parental stocks of maize. $\mathrm{A}$ is one of a series of genes affecting aleurone color, $A$ being colored and $a$ colorless: $S u$ is starchy and $s u$ is sugary endosperm; $\operatorname{Pr}$ is purple, and $p r$ is red aleurone color. ${ }^{\mathrm{a}}$

\begin{tabular}{|c|c|c|c|c|c|c|c|}
\hline \multirow[t]{3}{*}{ Treatment } & \multirow{3}{*}{$\begin{array}{c}\text { Total } \\
\text { number } \\
\text { of seeds }\end{array}$} & \multicolumn{6}{|c|}{ Endosperm deficiencies per 1000 seeds } \\
\hline & & \multicolumn{2}{|r|}{$a_{1}$} & \multicolumn{2}{|r|}{ Su } & \multicolumn{2}{|r|}{$\operatorname{Pr}$} \\
\hline & & Entire & Fractional & Entire & Fractional & Entire & Fractional \\
\hline $\begin{array}{l}\text { Virus- } \\
\text { infected }\end{array}$ & 1,300 & 3.1 & 3.8 & 2.3 & 0.8 & 0.0 & 3.1 \\
\hline Control & 12,519 & 0.2 & 1.4 & 0.3 & 0.4 & 0.4 & 0.1 \\
\hline
\end{tabular}

aReproduced with permission from (51). Copyright 1963 by AAAS. 
Female parent, not infected aa $A 2 A 2 C 1 C 1 C 2 C 2 R R$, colorless kemel
Male parent, virus infected

AA A2A2 CIC1 C2C2 RR, colored kernel

\section{F1 Progeny}

Expected: $A a A 2 A 2 C 1 C 1 C 2 C 2 R R$

All kemels colored
Result: Most kemels colored but some partly or totally colorless

Conclusion: Reveals mutations at $\mathrm{A}$ locus

\section{Plant F1 kernels and self}

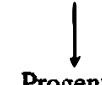

\section{Expected:}

$A A A 2 A 2 C 1 C 1 C 2 C 2 R R$, colored 2Aa A2A2 C1Cl C2C2 RR, colored aa $A 2 A 2 C 1 C 1 C 2 C 2 R R$, colorless 3 colored: 1 colorless
Result: Most ears have 3:1 ratio of colored:colorless, but a few do not

Select ear that does not have 3:1 ratio of colored:colorless

Plant colored and colorless kernels in separate rows

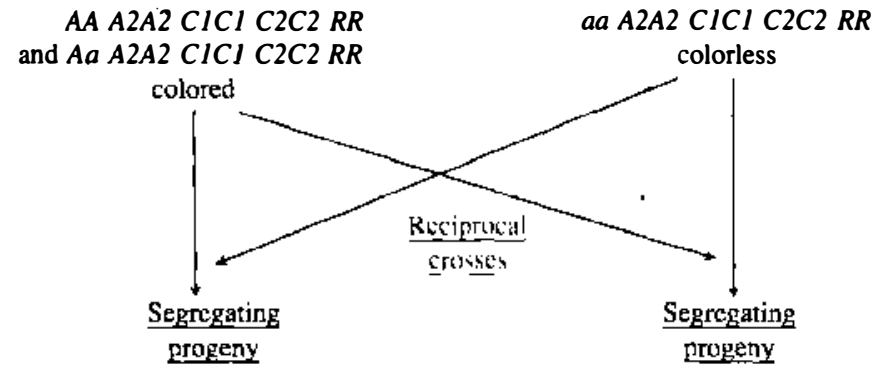

Expected genotypes:

Aa A2A2 CICI C2C2 RR

Aa A2A2 CIC1 C2C2 RR aa $A 2 A 2 C 1 C 1 C 2 C 2 R R$ aa $A 2 A 2 C 1 C 1 C 2 C 2 R R$

Expected ghenotype: colored:colorless 1:1 colored:colorless 1:1

Results: Many ears have segregation ratios significantly different than 1:1, confirming aberrant ratio.

Conclusion: Probably a mixture of following phenomena

1. Mutation at loci other than $A$, e.g. $C 1$ to $c 1 . A A A 2 A 2 c l c l C 2 C 2 R R$ is colorless

2. Activation of a controlling element expressed early in endosperm development

Figure 1 Diagrammatic representation of experiments demonstrating virus-associated mutations and aberrant ratio at " $A$ " locus. 
on the abnormal segregation ratios, but they continued to observe mutations in the later generations of progeny of virus-infected plants. These included a "Navajo mimic," tentatively located on chromosome 3, a "mosaic mimic" inherited maternally, a "yellow blotch" leaf pattem, and a "yellow-stripe" pattern (G. F. Sprague, personal communication; H. H. McKinney, personal memoirs, privately published). It is intriguing that one of these may have been a chloroplast mutant.

Mottinger (personal communication), in attempting to confirm the mutagenicity of BSMV infection, found two mutants at the $A d h-l$ locus among 309 kernels from 300 ears, each pollinated with an estimated 2000 grains of allyl-alcohol treated pollen. The rate, about $5 \times 10^{-6}$, is considerably higher than the spontaneous rate $\left(<2 \times 10^{-3}\right)$ for the Adh-1 locus (22). One of the mutants has a $3 \mathrm{~Kb}$ insertion in the Adh-1 gene (J. P. Mottinger, M. A. Johns, M. Freeling, personal communication). This research is continuing and, if larger numbers are obtained, could confirm the correlation between BSMV infection and mutation in a different maize line than that used by Sprague \& McKinney. A correlation implies causation but is not conclusive proof.

\section{Aberrant Ratio (AR)}

In further investigations of AR, Sprague \& McKinney $(49,50)$ applied pollen from virus-infected plants of the same stock used in studying mutations to silks of plants homozygous recessive for various of the marker loci. F1 plants were always selfed (Figure 1). Some F2 ears deviated from the expected 3:1 ratio of kemels with dominant:recessive phenotype. Either phenotype could be in excess of expected. These ears were considered tentative cases of AR. Recessive and dominant phenotype kemels from F2 ears showing tentative AR were planted in separate rows and reciprocal crosses made between pairs of plants to produce progeny. The segregating progeny ears should have had a 1:1 ratio of dominant and recessive phenotypes. If both ears deviated by more than two standard deviation units from a 1:1 ratio, AR was considered confirmed. Cases where only one of the reciprocal crosses gave a deviant ratio were discarded. Subsequent generations of AR stocks were likewise maintained by reciprocal crosses of plants from kernels of recessive and dominant phenotype. The expected segregation ratio was always $1: 1$. Reciprocal crosses were made to more easily detect some of the known phenomena that lead to distortion in one direction only.

Control crosses were also made between uninfected plants of the dominantly marked male parent stock and plants of the various recessive, female lines. Some of the F2 ears from these control crosses also showed segregation ratios of marker loci that deviated from the expected by more than two standard deviation units. A low level of deviant segregation should occur on purely statistical grounds. Sprague \& McKinney (49) reported that 30 out of 2000 F2 control ears had unexpected segregation ratios. All 30 gave normal segregation 
Table 2 Individual ear records of male and female transmission of the $\mathrm{A}$ and a alleles derived from an AR stock. ${ }^{a}$

\begin{tabular}{|c|c|c|c|c|c|c|}
\hline \multirow{2}{*}{$\begin{array}{l}\text { Culture and } \\
\text { plant number }\end{array}$} & \multicolumn{3}{|c|}{ Female transmission } & \multicolumn{3}{|c|}{ Male transmission } \\
\hline & $A$ & $a$ & $\% a$ & $A$ & $a$ & $\% a$ \\
\hline $64: 748-1 \times 749-5$ & 117 & 138 & 54.1 & 113 & 180 & 61.4 \\
\hline $748-2 \times 749-18$ & 230 & 218 & 48.7 & - & - & - \\
\hline $748-3 \times 749-12$ & 214 & 193 & 47.4 & 210 & 198 & 48.5 \\
\hline $748-4 \times 749-15$ & 212 & 284 & 57.3 & 260 & 236 & 47.6 \\
\hline $748-5 \times 749-13$ & 54 & 99 & 64.7 & 119 & 237 & 66.6 \\
\hline $748-11 \times 749-2$ & 156 & 209 & 57.3 & 160 & 164 & 50.6 \\
\hline $748-14 \times 749-7$ & 232 & 229 & 49.7 & 159 & 190 & 54.4 \\
\hline $748-15 \times 749-6$ & 58 & 112 & 65.9 & 94 & 238 & 71.7 \\
\hline $748-16 \times 749-11$ & 155 & 257 & 62.4 & 102 & 106 & 51.0 \\
\hline $748-17 \times 749-17$ & 184 & 215 & 53.9 & 103 & 183 & 64.0 \\
\hline $748-19 \times 749-16$ & 121 & 339 & 73.7 & 86 & 328 & 79.2 \\
\hline
\end{tabular}

Reproduced with permission from (49).

in the subsequent generation. Thus none was confirmed as showing AR. In contrast, from a virus-infected male parent, "over 50" F2 ears with tentative AR gave "over 25" confirmed cases of AR, the exact number depending on classification of borderline cases. An example of phenotypic ratios observed in an AR stock is given in Table 2.

Three points must be kept in mind in reading Sprague \& McKinney's reports on $\operatorname{AR}(49,50)$. First they considered the virus to have affected the dominant alleles $(A, P r, S u, S h, W x)$, since the virus-infected parent was homozygous dominant at all these loci. The recessive alleles of the marker loci were never present in a virus-infected plant. The designation female transmission, or male transmission in Table 2 [and in other tables of Sprague \& McKinney $(49,50)$ ], refers to the plant from the kernel of the dominant phenotype, which was considered to have the dominant allele. Second, they considered that AR had two phases, one with an excess of dominant phenotype and the other with an excess of recessive phenotype. In the 1971 paper, these were designated as $A^{* a}$ and $\mathrm{Aa}^{*}$ respectively for stocks showing $\mathrm{AR}$ at the $A$ locus. A kernel designated $a a\left(\mathrm{~A}^{*} \mathrm{a}\right)$ was a colorless kemel from a stock showing an excess of colored kemels. Third, they assumed that the pedigree and phenotype reliably indicated genotype and reported only the inferred genotype, as is commonly done in genetics. Sprague \& McKinney (50) recognized the problem and that alleles could be masked. The presence or absence of aleurone color is subject to problems when used as a marker because it is under multigenic control. Consequently, phenotype is not always simply related to genotype. The AR stocks carry other recessive color factors not confined to the marker loci $(5,36$, 43). For purposes of discussion, consider the phenotype of colored aleurone 
controlled by alleles at several loci. Both parents were homozygous dominant at $A 2, C 1, C 2$, and $R$, and differed only at $A$. Mutation of a dominant $A$ allele to recessive $a$ in the virus-infected parent would be detected as a colorless kernel in the F1 generation. However, while the $A$ allele is marked in the mind of the experimenter, it is not thereby more susceptible to mutation than other loci. Mutation, for example, of a dominant $C l$ allele to the recessive would not have been detected in the $F l$ but would have been expressed as some colorless kernels in the $F 2$ and succeeding generations. Some of the colorless kernels would be $c l c l$, and using $a a$ to designate them confuses phenotype and genotype. Even though the problem is recognized on a theoretical basis, in practice designation of colorless kernels as aa may lead one to think of them as really genetically $a$ a rather than as "colorless kernels which by pedigree should be $a$ a but may possibly be $a 2 a 2, c 1 c 1, c 2 c 2$ or $r r$." It is an example of a desirable shortcut in communication leading to an undesirable bias in thought.

As reported by Sprague \& McKinney $(49,50)$, the main characteristics of $\mathrm{AR}$ are given below. These are generalizations drawn from a large amount of data. Results of individual experiments sometimes deviated from these generalizations. And some stocks deviated more or less consistently. For example, a WSMV-derived stock with "AR" at the su locus, used by Samson et al (43), "exhibited more distortion in the su su X Su su than the reciprocal" (G. F. Sprague, personal communication).

1. AR was observed in progeny of plants infected by BSMV, WSMV, and com lily fleck virus but not MDMV-strain B.

2. AR was observed in progeny of BSMV-infected plants only if the flag leaf had mosaic symptoms, implying the necessity for complete systemic invasion of the plant.

3. There was no specificity between the affected locus and the virus.

4. AR was locus specific. Stocks showing AR at one locus had normal segregation at other loci on the same or other chromosomes.

5. AR was maintained through at least eight generations of sib crosses.

6. Male and female transmission gave similar expression of AR.

7. AR was detected in all marker loci that were adequately tested.

8. The phase of AR usually remained the same in a given stock but sometimes it reversed. In the F3, both phases were usually observed erratically, but in subsequent generations the phase became fixed.

9. AR was expressed as an excess of either the dominant or recessive phenotype.

10. AR was occasionally lost or transferred to other loci.

11. The two gametes were produced in normal numbers. For example, crosses of $A a$ (AR) to $a$ a (normal) gave expected segregation ratios, though $\mathrm{AR}$ could be recovered in low frequency from progeny of such crosses. 
Tables 3 and 4 illustrate this last point. Crosses between $A a(\mathrm{AR})$ plants and $a$ $a$ (C) (i.e. a non-AR tester) gave nonnal segregation, indicating that the $A a$ (AR) plant was really $A a$. However, crosses between $A a(C)$ plants and $a a$ (AR) frequently gave $25 \%$ colorless instead of the expected $50 \%$. This indicates that the $a a(\mathrm{AR})$ plants were $A a$. Such data led Sprague \& McKinney (50) to postulate masked alleles, i.e. that the $A$ allele was masked and not expressed in $a a(\mathrm{AR})$, rendering the endosperm colorless. There was no explanation as to why the masked allele was not revealed in crosses with the $A a$ (AR) plants to $a$ (C).

Sprague \& McKinney $(49,50)$ considered as possible reasons for AR other known causes of unusual segregation, such as gametophyte factors, chromosomal aberrations, preferential segregation, mutations at epistatic loci, and controlling elements. However, no one of these phenomena could by itself explain all the observed behavior of AR and therefore could not be involved if AR were a single phenomenon. But it is not. Subsequent research has shown that several of these phenomena exist in AR stocks and together could account for a substantial part, if not all, of the published results on AR.

The first of these phenomena to be found in AR stocks obtained from Sprague was recessive alleles at epistatic loci. In contrast to Point 11 above,

Table 3 Summary of crosses between $A^{*} a . A a^{*}$, and $A a(C)$ heterozygotes and recessive phenotypes derived from the same stocks.

\begin{tabular}{|c|c|c|c|c|}
\hline \multicolumn{2}{|c|}{ Type of cross } & \multicolumn{3}{|c|}{$\begin{array}{l}\text { Number of reciprocal pairs exhibiting } \\
\text { the type of segregation indicated }\end{array}$} \\
\hline \multirow[t]{2}{*}{ Male } & Female & $A^{*} a^{\mathrm{a}}$ & $A a^{* \mathrm{~b}}$ & $A a(C)$ \\
\hline & (Seed from) & & & \\
\hline \multirow[t]{3}{*}{$A * a$} & $a a(A * a)^{c}$ & 6 & 16 & 4 \\
\hline & $\mathrm{aa}\left(\mathrm{Aa}^{*}\right)$ & 8 & 7 & 9 \\
\hline & $\mathrm{aa}(\mathrm{C})$ & 0 & 0 & 23 \\
\hline \multirow[t]{3}{*}{$\mathrm{Aa}^{*}$} & $a a(A * a)$ & 3 & 16 & 0 \\
\hline & $a a\left(A a^{*}\right)^{c}$ & 1 & 23 & 7 \\
\hline & $\mathrm{aa}(\mathrm{C})$ & 0 & 0 & 21 \\
\hline \multirow[t]{3}{*}{$\mathrm{Aa}(\mathrm{C})$} & $a a(A * a)$ & 12 & 0 & 6 \\
\hline & $\mathrm{aa}\left(\mathrm{Aa}^{*}\right)$ & 12 & 0 & 17 \\
\hline & $a a(C)^{d}$ & 0 & 0 & 21 \\
\hline \multicolumn{5}{|c|}{ 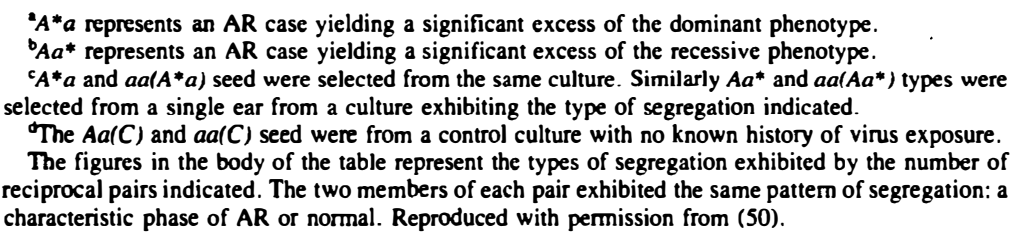 } \\
\hline
\end{tabular}


Table 4 Frequency of A and a phenotypes in a diallel series involving AR and control stocks

\begin{tabular}{|c|c|c|c|c|c|c|c|c|c|c|}
\hline \multirow[t]{3}{*}{ Pedigree number ${ }^{\mathrm{a}}$} & \multirow[t]{3}{*}{ Male parent } & \multicolumn{9}{|c|}{ Female parent } \\
\hline & & \multicolumn{3}{|c|}{$a a\left(A a^{*}\right)$} & \multicolumn{3}{|c|}{$a a\left(A^{*} a\right)$} & \multicolumn{3}{|c|}{$a a(\mathrm{C})$} \\
\hline & & $A$ & $a$ & $\% a$ & $A$ & $a$ & $\% a$ & $A$ & $a$ & $\% a$ \\
\hline $787-4$ & $A a^{*}$ & 20 & 61 & 75.3 & 64 & 156 & 70.9 & 129 & 186 & 51.3 \\
\hline-5 & & 116 & 161 & 58.1 & 235 & 422 & 64.2 & 179 & 223 & 55.5 \\
\hline $791-4$ & & 125 & 131 & 51.2 & 89 & 196 & 68.8 & 149 & 165 & 52.5 \\
\hline $795-1$ & & 127 & 154 & 66.7 & 133 & 260 & 66.2 & 188 & 183 & 49.3 \\
\hline-8 & & 200 & 230 & 53.5 & 354 & 92 & 20.6 & 122 & 117 & 49.0 \\
\hline $799-5$ & $A^{*} a$ & 256 & 100 & 28.1 & 254 & 82 & 24.4 & 130 & 139 & 51.7 \\
\hline-6 & & 113 & 158 & 52.5 & 157 & 89 & 19.9 & 172 & 152 & 46.9 \\
\hline $807-1$ & & 55 & 10 & 15.4 & 200 & 80 & 28.6 & 106 & 114 & 51.8 \\
\hline-7 & & 58 & 186 & 65.2 & 123 & 193 & 61.1 & 195 & 194 & 49.9 \\
\hline $811-1$ & $A a(C)$ & 165 & 162 & 49.5 & 357 & 111 & 23.9 & 136 & 156 & 53.4 \\
\hline-6 & & 187 & 172 & 47.9 & 67 & 23 & 25.6 & 205 & 231 & 53.0 \\
\hline $815-2$ & & 190 & 163 & 46.2 & 287 & 110 & 27.7 & 114 & 124 & 52.1 \\
\hline-7 & & 174 & 172 & 49.7 & 218 & 85 & 28.0 & 160 & 174 & 52.1 \\
\hline $819-1$ & & 213 & 189 & 47.0 & 158 & 97 & 27.3 & 105 & 89 & 45.9 \\
\hline-4 & & 47 & 29 & 52.5 & 244 & 88 & 26.5 & 190 & 149 & 44.0 \\
\hline-6 & & 204 & 195 & 48.9 & 279 & 79 & 22.1 & 240 & 201 & 45.6 \\
\hline
\end{tabular}

aThese figures represent the pedigree and plant number of the individuals used as male parents. The numbers of the female parents are not included. Reproduced with permission from (50).

Samson et al (43) did not find normal segregation in progeny of $A a(\mathrm{AR})$ or $a a$ (AR) plants and $a a(C)$ plants. Their experiments were designed to search for AR expression in crosses between plants of AR stocks in which the AR had been induced by different viruses. Since Sprague \& McKinney $(49,50)$ had reported that AR was only observed when both parents of a cross were from AR stock, and not when one parent was of non-AR tester stock, it appeared that both parents must contribute a virus-induced factor. Such factors might be virus specific. Samson et al (43) obtained unexpected ratios in crosses between plants from different AR stocks, but also in crosses between these plants and non-AR testers. In only 4 of 10 crosses between an $A a$ (AR) and an $a a(C)$ plant did the progeny segregate 1:1 as expected. However, the ratios, while unexpected, were mostly recognizable ratios for Mendelian segregation and led Samson et al (43) to suggest that the AR stocks had recessive alleles at loci epistatic to $A$. Later, Brakke et al (5) reported recessive $r$ and $c l$ alleles, and Nelson (36) reported recessive $c 1$ and $c 2$ alleles in BSMV-derived stocks showing AR at the $A$ locus. Crosses between plants from colored and colorless kernels of all possible genotypes with recessive alleles at two loci could give 0 , $25,50,62.5$, and $75 \%$ colorless kemels. If recessive alleles were present at three loci, the possible percentages are $0,25,44,50,62.5,72,75,81$, and 
87.5. Within experimental error for typical progeny sizes, these values cover most of the range from $0-100 \%$.

Recessive alleles at epistatic loci would lead to a general excess of recessive phenotypes. Excess recessive phenotypes are more prevalent than deficiencies in the data of Sprague \& McKinney $(49,50)$. In AR stocks having recessive alleles at epistatic loci (e.g.c), the expected segregation ratio (1:1) on a particular ear does not mean that the parent genotypes were $A a$ and $a a$. They might have been $C c$ and $c c$. It also does not mean that the change induced by the virus has been necessarily lost.

The conclusion of point 6 (above) is also not universal. Nelson (36) investigated a stock that he obtained from Sprague as having AR at Su/su and giving an excess of sugary kemels. In reciprocal crosses to Golden Cross Bantam (su/su), this line gave normal segregation when it was the female parent, but not when it was the male parent. Nelson suggested that a gametophyte factor, linked to $\mathrm{Su} / \mathrm{su}$ and affecting pollen survival or function, could produce this distortion.

Mottinger (34) has postulated a small deletion in chromosome 4 to explain unequal male and female transmission of $A R$ at the sugary locus. In this line, an excess of $S u$ phenotype was observed. Further experiments are needed to test this hypothesis.

Controlling elements have also been found in AR stocks. Spotted and sectored kemels are observed frequently in these stocks. Sprague selected a spotted kemel from AR stock induced by WSMV, selfed the resulting plant, and sent the ear to Peterson for analysis. Friedemann \& Peterson $(24,38)$ found a new controlling element system (Uq ruq) in the progeny. In addition, Sprague has evidence for another controlling element system in AR stocks (G. F. Sprague, personal communication).

Mottinger et al (35) reported mutations in $s h$ and $b z$ loci in progeny from a cross between an AR stock and another stock. These mutations involved DNA rearrangements and possible insertions. A number of cases of somatic loss of $s h, b z$, and $w x$, all on the short arm of chromosome 9, were observed. These phenomena could have resulted from a controlling element system in the AR stock, but this is not yet proven.

All of these tests have been done on AR stocks that Sprague took to Illinois for further testing upon his retirement from the US Department of Agriculture. They represent a small, possibly non-representative sample of AR stocks. The remainder of the stocks, left in storage in Beltsville, have been lost (G. F. Sprague, personal communication). It is premature to conclude that phenomena thus far reported are the complete list of abnormalities associated with virus infection.

Sprague \& McKinney (50) postulated that AR stock contained masked alleles, i.e. that the phenotype did not accurately reflect the genotype. They also considered that the simplest explanation of AR was that it was some type of 
paramutation (6). As observed in maize, paramutagenesis has been confined to certain loci. Of the loci involved in AR research, only $R$ has been shown to undergo paramutagenesis, which is a directed change in an allele conditioned by the allele at the same locus in the other chromosome of the diploid pair. The molecular mechanisms involved in paramutagenesis are unknown, and how this phenomenon might relate to AR or masking is unclear.

To test their theory of masked alleles, Sprague \& McKinney (50) selfed plants from $A^{*} a$ and $A a^{*}$ stocks. Selfed plants from colorless kernels of $A^{*} a$ stock gave all colorless progeny, as expected. But of 1200 ears obtained by selfing plants from colored kernels, $0.7 \%$ gave only colorless kernels. They also selfed plants from an $A a^{*}$ stock. In this case, all plants from the colored seed gave segregating progeny as expected, but $2.8 \%$ of the progeny from colorless seed gave segregating progeny, which was unexpected. The authors. considered this evidence for masked alleles, masked $a$ in the case of $A^{*} a$ stock, and masked $A$ in the case of $A a^{*}$ stock.

\section{Conclusions and Speculations}

AR appears to be not one phenomenon, but several. Two questions may be raised concerning it: (a) do the proposed explanations account for all cases of $\mathrm{AR}$, and $(b)$ were the different phenomena observed in AR stocks caused by the virus infection?

With regard to the first question, the proposed explanations can account for most if not all of the published results. Recessive alleles at epistatic loci, e.g. $c l, c 2$, or $r$, usually, but not always, yield excess recessive phenotypes. Most of the data reported by Sprague \& McKinney $(49,50)$ show an excess of recessive phenotypes. Even the cross between two plants ( $A$ and $a$ ) of an $A^{*} a$ stock (having an excess of $A$ phenotype) gave 16 ears with an excess of colorless kernels $\left(A a^{*}\right)$ versus 6 with an excess of colored kernels $\left(A^{*} a\right)$ (Table $3)$. This result is compatible with recessive alleles at epistatic loci. However, this same series of crosses gave 4 ears with normal (1:1) segregation, which Nelson (36) has pointed out would not be expected. That is, the only case of excess colored phenotype that can arise in crosses between colorless and colored phenotypes with recessive alleles at two loci (e.g. $a$ and $c l$ ) is from a cross of the type $a \mathrm{aCl} \mathrm{Cl} \times A \mathrm{ACl} \mathrm{cl}$. Colorless progeny are $\mathrm{Aacl} \mathrm{cl}$, and colored $A a C l C l$ or $A a C l C l$. Neither possible cross between progeny pairs, i.e. $\mathrm{Aacl} c \mathrm{Cl} \times \mathrm{AaClCl}$, or $\mathrm{Aacl} c \mathrm{cl} \times \mathrm{AaCl} \mathrm{cl}$, would give $50 \%$ colorless kernels. A second explanation then has to be sought for these four ears.

McKinney \& Sprague $(49,50)$ always obtained normal segregation in crosses between AR stocks and homozygous recessive testers, i.e. Aa (AR) by $a a$ (C) (Tables 3 and 4), which would not be expected with AR stock carrying recessive alleles at epistatic loci or gametophyte factors unless the tested sample was limited. In the F3 and F4 generations, the colored kemels on more 
than half the ears should all be $A a$ in stocks showing AR because of recessive alleles at $a 2, c 1, c 2$, or $r$. In less than half the ears, one-third of the colored kernels would be $A A$ and two-thirds $A a$. Sprague \& McKinney made 23 and 21 crosses from plants grown from kernels from two different ears for the data of Table 3, and a total of nine crosses from plants from five different parent ears for the data of Table 4 (50). It is unlikely, but not impossible, that Sprague \& McKinney by chance used $A a$ plants, and not $A A$, for all these crosses. Sprague (personal communication) had many additional crosses of the same type, including reciprocals of those in Tables 3 and 4, which supported the general conclusion. It is impossible to evaluate these unreported data statistically.

The occurrence of segregating progeny after selfing a plant from an $a a\left(\mathrm{Aa}^{*}\right)$ kernel, and of all colorless progeny after selfing a $A a(A * a)$ kernel (50), is also hard to explain on the basis of recessive alleles at epistatic loci, gametophyte factors, or loss of chromosome segments. However, these results could be explained if the phenotype of the endosperm differed from the genotype of the embryo because of heterofertilization or expression of a controlling element early in endosperm development.

Recessive alleles at epistatic loci may explain most AR cases at the " $a$ " locus, but not those at other loci, such as su. No epistatic loci are known for su. These may have other explanations, and it is notable that the Ugrug system was isolated from a Susu* stock $(24,38)$. A gametophyte factor was identified in a $\mathrm{Susu}^{*}$ stock (36) and loss of a chromosome segment was postulated in a $\mathrm{Su}^{*}$ su stock (34).

Two controlling element systems have been identified in AR stocks [ $(24$, 38); G. F. Sprague, personal communication)]. Such elements may participate in the inactivation of dominant alleles and in the other virus-associated mutations. In addition, they might explain AR phenomena not otherwise explainable. An element activated early enough in endosperm development could change the phenotype of the entire kemel, from dominant to recessive or vice versa, to give a phenotype different from the genotype of the embryo. Such a system would appear to "mask" alleles and could give a variety of apparent segregation ratios, depending on frequency of its activation.

Did the virus infection cause mutations and all these different phenomena found in AR stocks? Two reservations prevent a firm conclusion. First, the data show a correlation between virus infection and mutations and $A R$, which implies, but does not prove, cause. Second is the length of time between studies showing the presence of epistatic alleles, controlling elements, etc, and the cross with a virus-infected plant. Most studies have been confined to a small sample of AR stocks obtained from Sprague. These stocks were maintained for several generations by paired matings between sibs of contrasting phenotype. Control stocks maintained similarly through an equal number of generations and grown under the same conditions are not available. Despite these reserva- 
tions, it is interesting to consider possible mechanisms by which virus infection might have caused mutations and AR. Five explanations have been advanced.

1. The virus, or its RNA, persists in the plants by seed and/or pollen transmission and causes mutations and the AR phenomena. This seems unlikely. All attempts to recover infectious virus, or infectious RNA, to detect viral antigen or detect incorporation of ${ }^{32} \mathrm{P}$ into viral RNA have failed $(40,49,50)$. AR plants have no virus symptoms but are susceptible to reinfection $(4,30)$.

2. The viral genome as a cDNA copy, or a portion thereof, is integrated into maize DNA, where it is transmitted from generation to generation and regulates expression of adjacent genes. This possibility has not been eliminated, though there is evidence against it. First, there is no specificity between the inducing virus and the affected gene. BSMV and WSMV are unrelated. Sprague \& McKinney $(49,50)$ stated that AR had been induced at all loci that were adequately investigated. Integration probably involves recognition sequences and it is unlikely that these viruses have base sequences in common and in common with each of the alleles involved. Second, two groups of investigators have failed to detect BSMV sequences by nucleic acid hybridization using cloned BSMV cDNA as a probe under conditions that should detect single copies [(54); J. Mottinger and M. Freeling, personal communication]. The cDNA was not a full copy of the viral genome, so there is still a small chance that a short piece of viral genome may be present.

3 . The virus disease stresses the plant and activates natural controlling elements by an unspecified mechanism $(24,38)$. The timing and frequency of action of the controlling element(s) might be different from those of known elements. Peterson \& Friedemann point out that controlling elements have been found in com subjected to ionizing radiation, or after cycles of bridgebreakage-fusion in chromosomes, both of which may be considered stresses. The high rate of chromosomal abnormalities in plant callus and protoplast cultures is evidence that stressed plant cells mutate readily (14). The increased incidence of triploids and aneuploids in BSMV-infected wheat and barley supports the contention that virus infection can act as a stress factor to alter chromosomal replication in plants (44). If stress can cause activation of controlling elements, more direct evidence that virus infection is sufficient stress is needed.

4. Multiplication of the virus in differentiating tassel meristems interferes with nucleic acid repair and proof-reading systems, thereby increasing the observed mutation rate (4). No mechanism for such an interference has been suggested.

5. The virus may serve as a vector for the transfer of a host-controlling element or a regulatory RNA. Siegel (46) has reported encapsidation of plant nucleic acids into virions of tobacco mosaic virus (TMV) and the phenomenon may be common. Many researchers, upon finding evidence of homology 
between nucleic acid from purified virions and host nucleic acid, conclude that they simply did not purify the virions well enough. McKinney (personal communication) argued against the possibility of an active host RNA in pseudovirions because AR was observed only in progeny from plants with mosaic on the flag leaf, implying the necessity of complete systemic invasion of the plant. Presumably, systemic invasion of tassel meristem is crucial. If the mutations depend on a host nucleic acid introduced in a pseudovirion, one has to postulate that systemic invasion of the plant by this host nucleic acid depends on systemic invasion by the virus. McKinney considered such a dependence unlikely, but there is actually little evidence on which to judge whether such a dependence is likely or not. Plants have an RNA-dependent RNA polymerase, which is present in a much higher concentration in virus-infected than in non-infected plants $(17,21)$. The function of this enzyme is unknown, nor does present theory have an obvious role for it. However, it is known that DNA replication is primed by RNA. A regulatory role for RNA in the transcription of DNA has been proposed $(7,41)$. If there is a host regulatory RNA replicated by a host RNA-dependent RNA replicase, and if this regulatory RNA is transferred in a pseudovirion, then the stimúlation of this enzyme by virus infection might explain why systemic invasion of the plant by the regulatory RNA would be synchronous with invasion by the virus.

\section{Implications of Virus-Induced Mutations}

From an evolutionary viewpoint, high mutation rates associated with virus disease could increase the adaptability of plants and their survival under stress. The presence of mutator genes and transposons can confer an advantage to bacteria under certain conditions $(9,10)$. This is one of the few potential advantages that a plant virus might confer to its host.

From a practical viewpoint, the incidence of mutations associated with virus disease is low and should not be a big problem in maintaining pure lines. In any case, the problem, if there is one, has always been with us, but unrecognized.

From a theoretical viewpoint, the genetic changes associated with virus disease are interesting phenomena with many unanswered questions. The partial explanation of what has occurred does not lessen the curiosity as to why and how it occurred.

\section{ACKNOWLEDGEMENTS}

The author wishes to thank G. F. Sprague, E. H. Coe, P. A. Peterson, O. Nelson, J. Mottinger, and T. Carroll for reading this manuscript and for many stimulating and informative discussions. Appreciation is also due to G. F. Sprague for providing corn lines for the author's research in this area, to R. G. Samson, D. Pring, A. Jackson, and L. Lane for collaboration in that research, and to H. H. McKinney for ideas and support. 


\section{Literature Cited}

1. Brakke, M. K. 1971. Wheat streak mosaic virus. Descr. Plant Viruses, No. 48. Assoc. Appl. Biol./Commonw. Mycol. Inst., Surrey, England

2. Brakke, M. K., Van Pelt; N. 1970. Properties of infectious ribonucleic acid from wheat streak mosaic virus. Virology 42:699-706

3. Brakke, M. K., Palomar, M. K. 1976. Separation of components of barley stripe mosaic virions by density-gradient centrifugation. Virology 71:255-61

4. Brakke, M. K., Samson, R. G. 1981. Effect of temperature on susceptibility of normal and aberrant ratio com stocks to barley stripe mosaic and wheat streak mosaic viruses. Phytopathology 71:82324

5. Brakke, M. K., Samson, R. G., Compton, W. A. 1981. Recessive alleles found at $\mathbf{R}$ and $\mathrm{C}$ loci in maize stocks showing aberrant ratio at the A locus. Genetics 99:481-85

6. Brink, R. A., Styles, E. D., Axtell, J. D. 1968. Paramutation: Directioned genetic change. Science 159:161-70

7. Britten, R. J., Davidson, E. H. 1969. Gene regulation for higher cells: A theory. Science 165:349-57

8. Burk, L. G., McKinney, H. H. 1965. False virus symptom, a genetic defect of tobacco. J. Hered. 6:297-300

9. Chao, L., Vargas, C., Spear, B. B., Cox, E. C. 1983. Transposable elements as mutator genes in evolution. Nature 303:633-35

10. Chao, Y., Cox, E. C. 1983. Competition between high and low mutating strains of Escherichia coli. Evolution 37:125-34

11. Chen, S. M., Coe, E. H. Jr. 1977. Control of anthocyanin synthesis by the C locus in maize. Biochem. Gen. 15:33346

12. Chourey, P. S., Nelson, O. E. 1976. The enzymatic deficiency conditioned by the shrunken-1 mutations in maize. Biochem. Gen. 14:1041-55

13. Coe, E. H. Jr., Neuffer, M. G. 1977. The genetics of com. In Corn and Corn Improvement, ed. G. F. Sprague, pp. 111234. Madison, Wisc: Am. Soc. Agron.

14. d'Amato, F. 1975. The problem of genetic stability in plant tissue and cell cultures. In Crop Resources for Today and Tomorrow, ed. O. Frankel, J. G. Hawkes, pp. 333-48. London: Cambridge Univ. Press

15. Dooner, H. K. 1980. Genetic regulation of anthocyanin biosynthesis in maize. Genetics 94:s29
16. Dooner, H. K., Nelson, O. E. 1979. Interaction among $C, R$, and $V_{p}$ in the control of $\mathrm{Bz}$ glucosyl transferase during endosperm development in maize. $G e$ netics 91:309-15

17. Dorssers, L., Van Der Meer, J., Van Kammen A., Zabel, P. 1983. The cowpea mosaic virus RNA replication complex and the host-encoded RNAdependent RNA polymerase-template complex are functionally different. Virology 125:155-74

18. Fedoroff, N. V. 1982. Controlling elements in maize. In Mobile Genetic Elements, ed. J. Shapiro, pp. 1-63. New York: Academic

19. Fedoroff, N. V., Wessler, S., Shure, M 1983. Isolation of the transposable maize controlling elements Ac and Ds. Cell 35:235-42

20. Fincham, J. R. S., Sastry, G. R. K. 1974. Controlling elements in maize. Ann. Rev. Genet. 8:15-50

21. Fraenkel-Conrat, H. 1983. RNA-dependent RNA polymerases of plants. Proc. Natl. Acad. Sci. USA 80:422-24

22. Freeling M. 1977. Spontaneous forward mutation versus reversion frequencies for maize Adhl in pollen. Nature 267:154 56

23. Freeling, M., Cheng, D. S. K. 1978. Radiation-induced alcohol dehydrogenase mutants in maize following allyl alcohol selection of pollen. Genet. Res. 31:107-29

24. Friedemann, P., Peterson, P. A. 1982. The Uq controlling-element system in maize. Mol. Gen. Genet. 187:19-29

25. Gustafson, G. D., Larkins, B. A., Jackson, A. O. 1981. Comparative analysis of polypeptides synthesized in vivo and in vitro by two strains of barley stripe mosaic virus. Virology 111:579-87

26. Gustafson, G. D., Milner, J. J., McFarland, J. E., Pedersen, K., Larkins, B. A, Jackson, A. O. 1982. Investigation of the complexity of barley stripe mosaic virus RNAs and recombinant DNA clones. Virology 120:182-93

27. Jackson, A. O., Brakke, M. K. 1973. Multicomponent properties of barley stripe mosaic virus ribonucleic acid. Virology 55:483-94

28. Lane, L. C. 1974. The components of barley stripe mosaic and related viruses. Virology 58:323-33

29. Linde-Laursen, I., Siddiqui, K. A. 1974. Triploidy and aneuploidy in virus infected wheat, Triticum aestivum. Hereditas 76:152-54 
29a. McFarland, J. E., Brakke, M. K., Jackson, A. O. 1983. Complexity of the Argentina mild strain of barley stripe mosaic virus. Virology 130:397-402

30. McGir, S. C., Endrizzi, J. E. 1978. The effects of $B, K 10$, and $A R$ chromosomes on the resistance of maize to viral infection. Genetics 90:331-38

31. McKinney, H. H. 1929. Mosaic diseases in the Canary Islands, West Africa and Gibraltar. J. Agric. Res. 29:557-78

32. McKinney, H. H. 1935. Evidence of virus mutation in common mosaic of tobacco. J. Agric. Res. 51:951-81

33. McKinney, H. H. 1965. Biological characteristics of barley stripe-mosaic virus strains and their evolution. Washington, DC: US Dept. Agric. Techni. Bull. 1324

34. Mottinger, J. 1982. More on aberrant ratio. Maize Genet. Coop. Newsl. 56:8489

35. Mottinger, J. P., Dellaporta, S. L., Keller, P. B. 1984. Stable and unstable mutations in aberrant ratio stocks of maize. Genetics. In press

36. Nelson, O. E. 1981. A reexamination of the aberrant ratio phenomenon in maize. Maydica 26:119-31

37. Neuffer, M. G., Coe, E. H. Jr. 1975. Com (maize). Handbook of Genetics, ed. R. C. King, 2:3-30. New York: Plenum

38. Peterson, P. A., Friedmann, P. O. 1983. The ubiquitous controlling element system and its distribution in assorted maize testers. Maydica 28:213-49

39. Pirone, T. P. 1972. Sugarcarte mosaic virus. Descr. Plant Viruses, No. 88. Assoc. Appl. Biol./Commonw. Mycol. Inst., Surrey, England

40. Pring, D. R. 1974. Barley stripe mosaic vinus infection of com and the aberrant ratio genetic effect. Phytopathology 64: 64-70

41. Reanney, D. C. 1975. A regulatory role for viral RNA in eukaryotes. J. Theor. Biol. 49:461-92

42. Rubin, G. M., Spradling, A. C. 1982. Genetic transformation of Drosophila with transposable element vectors. Science 218:348-53

43. Samson, R. G., Brakke, M. K., Compton, W. A. 1979. Evidence for gene inactivation in the virus-induced aberrant ratio phenomenon in maize. Genetics 92:1231-39

44. Sandfaer, J. 1973. Barley stripe mosaic virus and the frequency of triploids and aneuploids in barley. Genetics 73:597603

45. Schwartz, D., Osterman, J. 1976. A pollen selection system for alcohol-dehydrogenase negative mutants in plants. Genetics 83:63-65

46. Siegel, A. 1971. Pseudovirions of tobacco mosaic virus. Virology 46:50-59

47. Spradling, A. C., Rubin, G. M. 1982. Transposition of cloned $\mathrm{P}$ elements into Drosophila germ line chromosomes. Science 218:341-47

48. Sprague, G. F. 1932. The nature and extent of hetero-fertilization in maize. Genetics 17:358-78

49. Sprague, G. F., McKinney, H. H. 1966. Aberrant ratio: An anomaly in maize associated with virus infection. Genetics 54:1287-96

50. Sprague, G. F., McKinney, H. H. 1971. Further evidence on the genetic behaviour of AR in maize. Genetics 67: $533-42$

51. Sprague, G. F., McKinney, H. H., Greeley, L. 1963. Virus as a mutagenic agent in maize. Science 141:1052-53

52. Stadler, L. J., Sprague, G. F. 1936. Genetic effects of ultra-violet radiation in maize. I. Unfiltered radiation. Proc. Natl. Acad. Sci. USA 22:572-78

53. Tsai, C. Y. 1974. The function of the waxy locus in starch synthesis in maize endosperm. Biochem. Genet. 11:83-96

54. Wienand, U., Peterson, P., Saedler, H. 1983. Hybridization studies of barley stripe mosaic virus cDNA clones to virus induced maize mutants. Maize Genet. Coop. Newsl. 57:157-58 